\title{
ADOLESCENTES EM CONFLITO COM A LEI: Um olhar sobre o processo Educacional Institucional
}

\author{
TEENS IN CONFLICT WITH THE LAW: A view at the institutional educational process
}

\section{ADOLESCENTES EN CONFLICTO CON LA LEY: Una mirada al proceso educativo institucional}

\author{
Valdenôra Torres Coura ${ }^{1}$ \\ Helder Neves de Albuquerque 2
}

1. Pedagoga. Mestre em Educação. Pedagoga do Complexo Lar do Garoto e Internação Provisória em Lagoa Seca-PB / Fundação Desenvolvimento da Criança e do Adolescente "Alice de Almeida". E-mail: valdenoratorresc@hotmail.com

2. Biólogo. Doutor em Educação. Professor da Editora Mentes Abertas e da ESL Consultoria. E-mail: postrad@mentesabertas.com.br

\begin{abstract}
RESUMO: Objetivou-se analisar as questões educacionais com base nos processos de execução de medidas socioeducativas das/os adolescentes que cometeram atos infracionais. O universo da pesquisa foi composto 21 participantes, sendo seis profissionais (um pedagogo, um psicólogo e quatro assistentes sociais) e quinze (15) adolescentes que cometeram atos infracionais e estão sob medidas socioeducativas no Lar do Garoto em Lagoa Seca-PB. Para isto, utilizou-se a aplicação de questionário com questões abertas. De acordo com os técnicos, as medidas socioeducativas são essenciais na ótica da responsabilidade jurídica, porém, o simples cumprimento dessas medidas não é suficiente para que os adolescentes se posicionem diante dos seus atos e rompam com as práticas infracionais. Afirmaram, também, do ponto de vista educacional, que no Lar do Garoto, apesar de serem cumpridas as exigências legais, muito ainda precisa ser melhorado para que esses adolescentes estejam aptos a exercerem em sua plenitude suas funções sociais.
\end{abstract}

Palavras-chave: Medida Socioeducativa Ato Infracional. Desenvolvimento Humano.

\begin{abstract}
The objective was to analyze educational issues based on the processes of implementing socio-educational measures of adolescents who committed infractions. The research universe was composed of 21 participants, six professionals (a pedagogue, a psychologist and four social workers) and fifteen (15) adolescents who committed infractions and are under socioeducational measures at Lar do Garoto in Lagoa Seca-PB. For this, the questionnaire with open questions was used. According to the technicians, socio-educational measures are essential from the point of view of legal responsibility, however, the simple fulfillment of these measures is not enough for adolescents to position themselves in relation to their actions and break with the infraction practices. They also stated, from an educational point of view, that in Lar do Garoto, despite the legal requirements being met, much still needs to be improved so that these adolescents are able to fully exercise their social functions.
\end{abstract}

Keywords: Social educational Measure. Infractional Act. Human development.
RESUMEN: El objetivo fue analizar la problemática educativa a partir de los procesos de implementación de medidas socioeducativas de los adolescentes que cometieron infracciones. El universo de investigación estuvo compuesto por 21 participantes, seis profesionales (un pedagogo, un psicólogo y cuatro trabajadores sociales) y quince (15) adolescentes que cometieron infracciones y se encuentran bajo medidas socioeducativas en Lar do Garoto en Lagoa Seca-PB. Para ello, se utilizó el cuestionario con preguntas abiertas. Según los técnicos, las medidas socioeducativas son fundamentales desde el punto de vista de la responsabilidad legal, sin embargo, el simple cumplimiento de estas medidas no es suficiente para que los adolescentes se posicionen en relación a sus acciones y rompan con las prácticas infractoras. También manifestaron, desde el punto de vista educativo, que en Lar do Garoto, a pesar de que se cumplen los requisitos legales, aún queda mucho por mejorar para que estos adolescentes puedan ejercer plenamente sus funciones sociales.

Palabras-clave: Medida socioeducativa. Acto infractor. Desarrollo humano. 


\section{Introducão}

O Estatuto da Criança e do Adolescente (ECA), no Brasil, surgiu para propiciar uma contribuição ampla e efetiva no encerramento de um capítulo obscuro da infância brasileira protagonizado pelo Código de Menores, uma Lei tida por muitos como discriminatória, repressiva e segregacionista, razão pela qual o ECA criado, por si tratar de uma legislação que se ajusta ao seu tempo e que, portanto, acompanha a evolução da sociedade (FARIA, 2017).

No entanto, mesmo com o surgimento do ECA, crianças e adolescentes brasileiros ainda têm seus direitos humanos fundamentais à vida, à saúde, à alimentação, à educação, ao esporte, ao lazer, à profissionalização, à cultura, à dignidade, ao respeito, à liberdade, à convivência familiar e comunitária, metodicamente ameaçados, desrespeitados e violados, inclusive pelo Estado, que a princípio deveriam proteger, defender, respeitar e oportunizar.

Com isso, também existem as normas e as penalidades, sendo as medidas socioeducativas aplicadas aos adolescentes infratores, a partir dos 12 anos, sob forma de sanção que visa punir, como também a dar oportunidades a eles para que não voltem a cometer novas infrações.

Talvez a solução dos problemas da violência e da criminalidade no país, possivelmente, seja propiciar oportunidades para que essas crianças e adolescentes possam desenvolver seus potenciais e realizar seus anseios, onde na maioria das vezes se baseiam, apenas, em ter um lar, uma família e uma escola. Cabendo ao Estado, desempenhar o seu papel de implantar políticas públicas e sociais de prevenção e proteção ao menor.

Devemos refletir muito sobre se o combate à violência pode se restringir apenas ao debate sobre a redução da maioridade penal. O Brasil precisa garantir um sistema socioeducativo que interrompa essa trajetória e ofereça oportunidades efetivas de ressocialização e cidadania para essas crianças e adolescentes.

Temos que evidenciar que houve conquistas e avanços na proteção aos direitos das crianças e adolescentes, contudo, ainda é preciso avançar muito mais para que esses direitos conquistados se mostrem efetivos, por intermédio da ressocialização dos adolescentes infratores, impedindo a reincidência criminal e seus efeitos colaterais nocivos. E que as Instituições ressocializadoras oportunizem e formem de verdade.

De acordo com o Estatuto da Criança e do Adolescente, a internação consiste em uma medida privativa de liberdade, aplicada pela autoridade judiciária, podendo ser revista a qualquer tempo, ou até alterada, conforme o parecer da equipe técnica do Ministério Público.

Quais são os casos nos quais são aplicadas as medidas socioeducativas de internação? Nos casos considerados graves como homicídio, assaltos, com ameaças à vida humana, e/ou outras infrações sequenciadas.

Vários fatores contribuem para que o adolescente cometa infrações. Dentre eles, podemos destacar: adesão ao uso indiscriminado de drogas, ociosidade, abandono, situações de ruas e/ou outras situações que o torna vulnerável a situação de elevado risco.

Podemos considerar também que a evasão escolar é também um dos fatores preponderantes para que o socioeducando, tornando-se mais ocioso, fica mais propenso a se envolver em situação de conflito com a Lei. A família, por sua vez, tem as suas fragilidades e nem sempre valorizam o processo educativo e não conseguem incentivar o adolescente a permanecer na escola. 
Isso constitui uma dificuldade na execução das medidas socioeducativas. Enquanto interno, o socioeducando demonstra-se buscando oportunidades para quando ficar em liberdade, dê uma melhoria na sua qualidade de vida. Deparamo-nos aí com problemas diversos: faixa etária diversificada e pouco aprendizado na escola convencional, sem muita perspectiva de um engajamento numa atividade remunerada, pelo baixo nível de conhecimento intelectual que possui.

Neste sentido, a justificativa deste trabalho reside no fato de que, no mundo de hoje, a dinâmica de trabalho e a vida atribulada acaba por impossibilitar a reflexão das pessoas acerca dos motivos que ensejam a criminalidade entre adolescentes, dificultando a aplicação dos programas de políticas públicas de forma eficaz, os quais, no papel, parecem bons, mas que na prática, muitas vezes, não apresentam os resultados almejados, o que justifica esse estudo e a elaboração de trabalho voltado à verificação do efeito das medidas socioeducativas, aplicadas aos adolescentes infratores, no âmbito do Lar do Garoto no município de Lagoa Seca-PB. Assim, este estudo objetivou analisar as questões educacionais com base nos processos de execução de medidas socioeducativas das/os adolescentes que cometeram atos infracionais e estão no Lar do Garoto Padre Otávio Santos em Lagoa Seca-PB.

\section{Procedimentos Metodológicos}

$\mathrm{O}$ estudo em questão tratou-se de uma pesquisa exploratória-descritiva com abordagem qualitativa e quantitativa com técnica de uso de questionário com questões abertas.

O universo da pesquisa foi composto por 6 (seis) profissionais diretamente empenhados na aplicação de medidas socioeducativas (um pedagogo, um psicólogo e quatro assistentes social) e com 15 (quinze) adolescentes que cometeram atos infracionais e estão sob medidas socioeducativas no Lar do Garoto em Lagoa Seca-PB. A definição da quantidade de pesquisados que integram a amostra se baseou na literatura sobre pesquisa qualitativa.

Para cumprir os requisitos da Bioética e adaptando do estudo de Celistre (2002), os pesquisados foram identificados por códigos, conforme a sequência de coleta de dados a critério da pesquisadora, sendo para os profissionais usados os códigos P1, .., P5, P6, e para os adolescentes os códigos J1, J2, ..., J14, J15.

Desta forma, optou-se por usar como instrumento de coleta de dados questionários, os quais foram validados por Zanella (2008) e revalidado por Zanella et al. (2010), e adaptados para esta pesquisa. O referido instrumento foi constituído por questões abertas, sendo aplicados ao pedagogo, um psicólogo e quatro assistentes sociais e aos 15 (quinze) adolescentes que cometeram atos infracionais e estão sob medidas socioeducativas no Lar do Garoto em Lagoa Seca-PB. Portanto, destaca-se que o questionário é uma das técnicas disponíveis, mais importantes para a obtenção e registro dos dados. Sua versatilidade permite utilizá-lo como instrumento de investigação e de avaliação de pessoas, processos e programas de formação. É uma técnica de avaliação que pode incorporar aspectos quantitativos e qualitativos (GARCIA, 2018).

A aplicação dos questionários ocorreu no mês de setembro do ano de 2019 e o processo de coleta de dados ocorreu da seguinte forma: ao ser autorizado pelo Comitê de Ética em Pesquisa com seres humanos e pela Instituição pesquisada, a pesquisadora entrou em contato com os técnicos que atuam no Lar do Garoto (pedagogo(a), psicólogo(a) e as assistentes sociais) para que pudesse ser apresentado o intuito e os objetivos da pesquisa, onde foi 
lido Termo de Consentimento Livre e Esclarecido (TCLE), e uma vez aceito a participação na pesquisa fosse assinado e devolvido uma cópia à pesquisadora. Em seguida foi entregue o questionário para que pudesse ser preenchido e devolvido à pesquisadora em um prazo máximo de 40 minutos.

Para a participação dos adolescentes, a pesquisadora responsável, entrou em contato com cada um dos pais ou responsáveis pelo adolescente incluído como possível participante da pesquisa para que pudesse ser apresentado o intuito e os objetivos da pesquisa e lido Termo de Consentimento Livre e Esclarecido, e com a concordância, assinado e devolvido uma cópia à pesquisadora.

Foram observadas as normas éticas determinadas na Resolução 466/12 do Conselho Nacional de Saúde (CNS), na perspectiva de garantir o anonimato dos participantes, assim como a sua autonomia no que se refere no Consentimento Livre e Esclarecido e respeito à vida, objetivando o exercício pleno da autonomia (BRASIL, 2012).

Esta pesquisa foi autorizada pelo Comitê de Ética e Pesquisa da Universidade Estadual da Paraíba (UEPB) em 16 de setembro de 2019, conforme Parecer Consubstanciado do CEP/UEPB, através do Certificado de Apresentação para Apreciação Ética - CAAE 19460719.1.0000.5187 (Figura 7).

\section{Resultados e Discussão}

Todos os profissionais que atuam como técnicos no Lar do Garoto são do gênero feminino e possuem pelo menos 10 anos de atuação na área, com idades superiores a 37 anos (Quadro 1).

Apesar de existir seis profissionais na Instituição, segundo Brasil (2006) o Sistema Nacional de Atendimento Socioeducativo determina que cada psicólogo e Assistente Social atendam no máximo 20 (vinte) adolescentes e o pedagogo 50 (cinquenta), evidenciando aqui um déficit de profissionais, pois o Lar do Garoto Padre Otávio, no período da pesquisa atendia aproximadamente 108 adolescentes.

Quadro 1: Perfil profissional dos técnicos que atuam no Lar do Garoto. 2019

\begin{tabular}{|c|c|c|c|c|}
\hline Pesquisados & Idade & Formação & Tempo de atuação & Função \\
\hline P1 & 37 & Psicologia & 10 anos & Psicóloga \\
\hline P2 & 51 & Pedagogia & - & Pedagoga \\
\hline P3 & 60 & Serviço Social & 31 anos & Assistente Social \\
\hline P4 & 70 & Serviço Social & 44 anos & Assistente Social \\
\hline P5 & 70 & Serviço Social & 35 anos & Assistente Social \\
\hline P6 & 64 & Serviço Social & - & Assistente Social \\
\hline
\end{tabular}

Fonte: dados da Pesquisa.

De acordo com Bernardo (2011), em um estudo no Estado de São Paulo mais de 90\% dos participantes têm o terceiro grau completo ou em processo de conclusão. Além disso, dos $66 \%$ já formados, a grande maioria tem pósgraduação (exceto dois). De acordo com o SINASE “[...] é imprescindível à composição de um corpo técnico que tenha conhecimento específico na área de atuação profissional e, sobretudo, conhecimento teórico-prático em relação à especificidade do trabalho a ser desenvolvido" (BRASIL, 2006, p. 63).

A opinião das técnicas que responderam ao questionário é de que já ocorreram mudanças significativas na execução das medidas socioeducativas (Quadro 2), porém, muito ainda é necessário que seja feito por meio de 
políticas públicas mais eficazes que possam proporcionar aos adolescentes/jovens oportunidades de crescimento em todas as áreas da vida e de ser em protagonismo da sua própria história.

Quadro 2: Opiniões dos técnicos que atuam no Lar do Garoto sobre a Medida Socioeducativa (Estrutura e organização). 2019

\begin{tabular}{|c|c|}
\hline Pesquisados & Falas dos Pesquisados \\
\hline P1 & "São extremamente importantes e bem estruturados, só às vezes falta verba para funcionar melhor". \\
\hline P2 & "São de grande importância, mais existem impedimentos para a realização de tais serviços". \\
\hline P3 & "Há, ainda, muito a ser feito". \\
\hline P4 & "Ainda temos muito a caminhar quanto a organização e estruturação para proteger o adolescente”. \\
\hline P5 & "Os direitos são negados". \\
\hline P6 & "Falta mais organização na Instituição”. \\
\hline
\end{tabular}

Fonte: dados da Pesquisa.

As medidas socioeducativas desenvolvidas na Unidade não são privativas de liberdade, prevalecendo o caráter educativo ao punitivo. Assim, o objetivo é a proteção e a educação viabilizadas por meio de políticas públicas como: educação, formação profissional, trabalho, saúde, lazer, esportes, cultura, dentre outros.

Para Pereira e Sudnrack (2008), quando se investe na oferta de atendimentos socioeducativos em meio aberto possibilita-se o fortalecimento de vínculos familiares e comunitários e a inserção do adolescente em programas sociais, dada a presença da rede de atendimento do município.

Em relação ao Quadro 3, os profissionais pesquisados afirmam que percebem o trabalho realizado em relação aos adolescentes/jovens em cumprimento de Medidas Socioeducativas é pouco satisfatório.

No entendimento do grupo, é necessária mais organização institucional, maior empatia com a causa e maior entrosamento com as instituições que executam a política de atendimento às crianças, adolescentes e jovens. Porém, são os técnicos e educadores, os profissionais de fundamental importância no processo socioeducativo na medida em que são responsáveis pelo direcionamento das ações, garantindo a participação dos adolescentes e estimulando o diálogo permanente.

Quadro 3: Opiniões dos técnicos sobre como percebem o trabalho realizado em relação aos adolescentes/jovens em cumprimento de Medidas Socioeducativas. 2019

\begin{tabular}{|c|c|}
\hline Pesquisados & Falas dos Pesquisados \\
\hline P1 & "Pouco satisfatório, haja vista a pouca articulação entre os setores e atores que abrange a medida \\
socioeducativa".
\end{tabular}

Fonte: dados da Pesquisa.

O SINASE determina que os Programas Socioeducativos devam facilitar o acesso e oferecer, assessorados ou dirigidos pelo corpo técnico, atendimento psicossocial individual, e com frequência regular, atendimento grupal, atendimento familiar, atividades de restabelecimento e manutenção dos vínculos familiares, acesso à assistência jurídica ao adolescente e sua família dentro do Sistema de Garantia de Direitos (BRASIL, 2006). 
Segundo os técnicos, as parcerias e a utilização dos Serviços da Rede seriam principalmente em conjunto com CREAS, CAPS e CRAS (Quadro 4).

Os profissionais pesquisados também observaram que há uma grande demanda para os serviços de pequena e média complexidade, para os quais ainda se faz necessário melhoramento nos equipamentos sociais para atender a procura que se dá com elevada frequência.

Quadro 4: Opiniões dos técnicos sobre as parcerias e utilização dos Serviços da Rede e quais seriam os equipamentos sociais principais. 2019

\begin{tabular}{|c|c|}
\hline Pesquisados & Falas dos Pesquisados \\
\hline P1 & "CREAS e CRAS". \\
\hline P2 & "CREAS e CRAS". \\
\hline P3 & "Encaminhamentos, Assistências diversas; planejamento e execução das Medidas \\
\hline P4 & Socioeducativas". \\
\hline P5 & "Não. Acho que não existe vinculaçôes com esses serviços". \\
\hline P6 & "CREAS, CRAS e CAPS". \\
\hline
\end{tabular}

Fonte: dados da Pesquisa.

Ainda de acordo com Bernardo (2011), deve-se avaliar, periodicamente, o cumprimento das metas estabelecidas e se os objetivos foram alcançados junto aos adolescentes. Além disso, a instituição e os profissionais devem trabalhar em parceria com a rede de programas do município para o envolvimento da família e do adolescente junto à comunidade, condição importante para a ressocialização e para a ocupação natural junto aos estratos sociais, educacionais e econômicos da Sociedade (PEREIRA; SUDBRACK, 2008; BRASIL, 2006).

Para o grupo de técnicos pesquisados é necessário melhorar o envolvimento com as instituições e demais serviços que possam mudar a qualidade de vida dos adolescentes/jovens, em cumprimento de medidas socioeducativas (Quadro 5). As políticas públicas devem apontar propostas de ações sociais coerentes com a evolução do socioeducando, possibilitando o seu desenvolvimento psicossocial, familiar, educacional e comunitário, isto é, os segmentos deverão ser constituídos de opções para o seu engajamento e capacitação para o mercado de trabalho e exercício da cidadania.

Quadro 5: Opiniões dos técnicos sobre quais ações consideram que poderiam ser realizadas em prol dos adolescentes/jovens em cumprimento de Medidas Socioeducativas. 2019

\begin{tabular}{|c|c|}
\hline Pesquisados & Falas dos Pesquisados \\
\hline P1 & "Ações de saúde, trabalho e profissionalizante". \\
\hline P2 & "Ações de saúde e no campo profissional". \\
\hline P3 & "Incentivo à profissionalização; oportunidade de trabalho e cidadania". \\
\hline P4 & "Envolver a comunidade, instituições, e principalmente, os setores industriais aos \\
& Programas oferecidos pela Instituição". \\
\hline P5 & "Profissionalização e educação". \\
\hline P6 & "Mais educação e cursos de profissionalização". \\
\hline
\end{tabular}

Fonte: dados da Pesquisa. 
Apesar de todas as atividades serem bem desenvolvidas durante o cumprimento de Medidas Socioeducativas, para Bernardo (2011), ainda existe uma grande incoerência entre o que é prometido e o que é oferecido aos jovens, pois os aspectos ligados à marginalização e à exclusão são fortalecidos durante a medida.

Infelizmente a educação no sentido amplo fica à parte, pois os técnicos não têm como resolver as bases da criminalidade, violência e desigualdade social, os quais a atenção volta-se sempre para a vigia e o controle (SALIBA, 2006). Porém, em meio a tantos dessabores e dificuldades encontradas no sistema socioeducativo, existem experiências bem-sucedidas na área. Conforme Costa (2005), em uma unidade em Roraima, alguns trabalhos e projetos efetuados se mostraram transformadores todos os profissionais têm papel significativo na viabilização das propostas e projetos. Já, no Rio de Janeiro, um projeto de extensão universitária promovido pela Universidade do Estado do Rio de Janeiro deu aos adolescentes infratores, alternativas diferenciadas de inserção social, por meio da atividade de leitura, agregando os adolescentes e funcionários.

Na opinião dos técnicos pesquisados, falta ainda, vontade política para que tenhamos um sistema de garantia de direitos e participação da sociedade como corresponsável para que haja mais eficiência na execução do plano individual de atendimento ao socioeducando (Quadro 6). Observaram também, que há ainda uma grande resistência em se tratando do acolhimento do socioeducando para o cumprimento da medida que lhe foi aplicada.

Quadro 6: Opiniões dos técnicos sobre como os Serviços da Rede deveriam estar articulados para a garantia dos direitos básicos dos adolescentes em Medidas Socioeducativas. 2019

\begin{tabular}{|c|c|}
\hline Pesquisados & Falas dos Pesquisados \\
\hline P1 & $\begin{array}{c}\text { "O CREAS deveria estar mais junto para a após a desinternação garantir o acompanhamento para que o } \\
\text { jovem não retorne ao cometimento de novo Ato Infracional”. }\end{array}$ \\
\hline $\mathbf{P 2}$ & $\begin{array}{c}\text { "O não desmembramento setorial, para quando o adolescente fosse liberado, pudesse ter esse } \\
\text { fortalecimento, nos Serviços". }\end{array}$ \\
\hline P3 & "Saúde, Educação, Assistência Social, esporte, lazer e demais políticas públicas essenciais". \\
\hline P4 & $\begin{array}{c}\text { "Os serviços de saúde por exemplo, desde que nas Unidades, existe a ausência de médicos, enfermeiras e } \\
\text { dentistas". }\end{array}$ \\
\hline P5 & "Saúde, Profissionalização que o mercado de trabalho empregasse estes socioeducandos". \\
\hline P6 & $\begin{array}{c}\text { "Os serviços das Redes deixam a desejar. É preciso que as politicas públicas funcionem, pois também, } \\
\text { deixam a desejar”. }\end{array}$ \\
\hline
\end{tabular}

Fonte: dados da Pesquisa.

Quanto as opiniões dos técnicos sobre que mudanças as Medidas Socioeducativas podem proporcionar aos adolescentes, três técnicos não responderam (Quadro 7), porém os demais afirmaram que eles ficam mais responsáveis, profissionalização e volta a reestabelecer vínculos com a Sociedade, de uma forma geral.

Ao serem aplicadas as medidas socioeducativas, conforme estabelece o ECA, vislumbra-se a oportunidade de se dar um novo direcionamento à vida do adolescente/Jovens, construindo um projeto de vida no qual ele será o protagonista da sua "nova história". Entende-se, contudo, que uma série de fatores que precisam também ser mudados para essa mudança ocorra de verdade e a medida aplicada seja eficiente.

Quadro 7: Opiniões dos técnicos sobre que mudanças as Medidas Socioeducativas podem proporcionar aos adolescentes. 2019

\begin{tabular}{|c|c|}
\hline Pesquisados & Falas dos Pesquisados \\
\hline P1 & "Responsabilidade perante o Ato Infracional, engajamento na escola e cursos profissionalizantes; \\
& mudanças comportamentais com a maior maturidade". \\
\hline
\end{tabular}




\begin{tabular}{|c|c|}
\hline P2 & \\
\hline P3 & $\begin{array}{c}\text { “Se bem aplicada, a Medida Socioeducativa poderá após o seu cumprimento, reestabelecer vínculos, } \\
\text { proporcionando um Projeto de Vida”. }\end{array}$ \\
\hline P4 & $\begin{array}{c}\text { "Quando o adolescente observa e aceita que pode haver mudanças em sua vida, ele acata o que é } \\
\text { oferecido na escola e na profissionalização". }\end{array}$ \\
\hline P5 & - \\
\hline P6 & - \\
\hline
\end{tabular}

Fonte: dados da Pesquisa.

Sobre as opiniões dos técnicos de como percebem as famílias dos adolescentes em medidas socioeducativas, as respostas foram as mais diversas (Quadro 8), muito embora a maior parte delas fique alheias as suas responsabilidades quanto as medidas.

As famílias, independentes da sua modalidade, reconhecem a importância do seu papel na sociedade. A luta pela sobrevivência, principalmente daquelas que vivem abaixo da linha da pobreza, é considerado um dos fatores que contribuem para a sua fragilidade. As crianças, logo cedo, ganham o espaço de rua e são expostos a situações elevada de riscos, seja pessoal, social ou ainda, evadam-se da escola pela desvalorização da educação, e passam a se enveredar pelos caminhos ilícitos.

A participação da família no processo educativo ajuda a dar um novo rumo à vida do socioeducando. Nem sempre, porém, as famílias são conscientes da importância desse processo.

Quadro 8: Opiniões dos técnicos sobre como percebem as famílias dos adolescentes em medida socioeducativa. 2019

\begin{tabular}{|c|c|}
\hline Pesquisados & Falas dos Pesquisados \\
\hline P1 & "É boa. Só necessita de maior aproximação, pois elas têm que saber que são importantes nesse Processo \\
Educativo".
\end{tabular}

Fonte: dados da Pesquisa.

É imprescindível, portanto, que a composição de um corpo técnico possua conhecimento específico na área de atuação profissional e, sobretudo, conhecimento teórico-prático em relação à especificidade do trabalho a ser desenvolvido. Sendo assim, os programas socioeducativos devem contar com uma equipe multiprofissional com perfil capaz de acolher e acompanhar os adolescentes e suas famílias em suas demandas, além de possuir habilidade de acessar a rede de atendimento pública e comunitária para atender casos de violação, promoção e garantia de direitos (BRASIL, 2006, p. 63).

Para Cabral (2018), o princípio da integralidade ressalta que o adolescente deve ser atendido em suas múltiplas facetas e que, deste processo, devem participar a família, a comunidade e o Estado. Estas três instituições são peças importantes tanto para a construção da personalidade da/o adolescente quanto para a plena execução das medidas socioeducativas. Pelas/os adolescentes legalmente serem inimputáveis, a família tem papel fundamental na 
garantia do acesso aos seus direitos. Na ausência da família o Estado designa uma pessoa para assumir o papel de responsável legal.

Com base no ECA (BRASIL, 1990), uma vez norteado pelo princípio da integralidade, o SINASE (BRASIL, 2006) vem reforçar a importância da participação da família, comunidade e Estado no processo de execução das medidas socioeducativas. Em primeira instância a família por passar maior parte do tempo com a/o adolescente deve participar efetivamente de todo o processo.

De acordo com as opiniões dos técnicos sobre como classifica os serviços prestados aos adolescentes com medidas socioeducativas (Quadro 9), tais serviços, dentre eles, são satisfatórios, precários e ainda precisam melhorar e muito.

Quadro 9: Opiniões dos técnicos sobre como classifica os serviços prestados aos adolescentes com medidas socioeducativas. 2019

\begin{tabular}{|c|c|c|}
\hline Pesquisados & Serviços prestados & Falas dos Pesquisados \\
\hline \multirow{5}{*}{ P1 } & Saúde & "Precária". \\
\hline & Educação & "Satisfatória". \\
\hline & Esportes & "Satisfatória". \\
\hline & Lazer & "Satisfatória". \\
\hline & Cursos Profissionalizantes & "Necessita diversificar". \\
\hline \multirow{5}{*}{ P2 } & Saúde & "Precária". \\
\hline & Educação & "Satisfatória". \\
\hline & Esportes & "Satisfatória". \\
\hline & Lazer & "Satisfatória". \\
\hline & Cursos Profissionalizantes & "Precisa melhorar". \\
\hline \multirow{5}{*}{ P3 } & Saúde & "Precisa melhorar em todos os aspectos". \\
\hline & Educação & "Ainda há o que melhorar". \\
\hline & Esportes & - \\
\hline & Lazer & "Precisa de maior incentivo e recursos". \\
\hline & Cursos Profissionalizantes & "São insuficientes para a demanda". \\
\hline \multirow{5}{*}{ P4 } & Saúde & "Precária". \\
\hline & Educação & "Vivemos um progresso com a Escola Cidadã". \\
\hline & Esportes & "Precária, pois falta instalações e materiais". \\
\hline & Lazer & "Insuficiente". \\
\hline & Cursos Profissionalizantes & $\begin{array}{c}\text { "Muito proveitoso, pois foram oferecidos diversos cursos } \\
\text { profissionalizantes". }\end{array}$ \\
\hline \multirow{5}{*}{ P5 } & Saúde & "Não existe na Unidade". \\
\hline & Educação & "Tem uma escola integral". \\
\hline & Esportes & "Atende as necessidades dos socioeducandos". \\
\hline & Lazer & - \\
\hline & Cursos Profissionalizantes & - \\
\hline \multirow{5}{*}{ P6 } & Saúde & "Não existe por falta de infraestrutura". \\
\hline & Educação & $\begin{array}{c}\text { "Existe uma Escola Cidadão que funciona integral como também abundante } \\
\text { às necessidades dos internos". }\end{array}$ \\
\hline & Esportes & - \\
\hline & Lazer & - \\
\hline & Cursos Profissionalizantes & - \\
\hline
\end{tabular}

Fonte: dados da Pesquisa.

Mesmo os técnicos pesquisados sendo capacitados e exercendo suas funções de acordo com as leis, eles classificam os serviços prestados tanto de forma positiva quanto negativa. Se por um lado os jovens cometem atos 
infracionais pelas mais diversas causas (falta de uma religião na sua rotina diária, ausência da participação efetiva da família, residir em regiões de baixo poder aquisitivo, exposição excessiva à violência e ao tráfico de drogas entre os amigos e colegas mais próximos, dentre outros), por outro lado, o Estado fecha os olhos para essas questões, por serem "invisíveis sociais", as questões sociais, de violência e do tráfico não são resolvidas, com isso, deixando, cada vez mais, os jovens e suas famílias cada vez mais vulneráveis.

Na abordagem de Dantas (2016), é baixa a credibilidade em relação às medidas socioeducativas. Pois não surtem os efeitos necessários após o seu cumprimento, uma vez que tudo depende de como os adolescentes em conflito com a lei absorve tal aprendizado, porque alguns adolescentes entendem a medida como castigo, e por isso cumprem as medidas socioeducativas sem se preocupar com seu significado, considerando apenas como sendo uma medida punitiva de acordo com a Lei que deve ser cumprida, onde muitas vezes, tal pensamento, também se estende aos familiares e a própria sociedade em geral.

\section{RESPOSTAS DOS ADOLESCENTES PESQUISADOS}

De acordo com o projeto o grupo amostral deveria ter sido composto por 20 adolescentes a serem pesquisados, porém, ao longo do percurso, intercorrências aconteceram, portanto, 5 (cinco) dos possíveis pesquisados tiveram sua medida conclusa, com isso Excelentíssimo Senhor Juiz da Infância e Juventude autorizou a saída deles da Instituição para entregar aos pais ou responsáveis, por conta disso, o total de pesquisados foi de 15 participantes.

Conforme a coleta das informações obtidas através do questionário, a infância dos socioeducandos foi marcada pelo carinho do grupo familiar, liberdade para brincar com os irmãos ou com "os colegas" residentes no mesmo bairro (Quadro 10).

Quadro 10: Falas dos pesquisados sobre fatos importantes de sua história de vida. 2019

\begin{tabular}{|c|c|}
\hline Pesquisados & Falas dos Pesquisados \\
\hline J1 & "Sim. A separação dos meus pais." \\
\hline $\mathbf{J} 2$ & "Infância boa, em companhia dos irmãos" Aos 13 anos começou a fazer coisas erradas. \\
\hline J3 & Infância normal, brincando com os irmãos e outras crianças da comunidade” \\
\hline J4 & "Normal. Brinquei muito com os "amigos da mesma rua" \\
\hline J5 & "Minha infância foi boa, brincando com os irmãos, apesar deles ser mais velho". \\
\hline J6 & "Foi boa". \\
\hline $\mathbf{J 7}$ & "Minha infância foi boa. Muito legal. Brinquei muito com meus irmãos e colegas de rua". \\
\hline J8 & "A infância foi boa, brinquei muito". \\
\hline J9 & "Foi muito boa, a minha infância". \\
\hline $\mathbf{J 1 0}$ & "Tive uma infância saudável". \\
\hline J11 & "Infância boa, brincando muito". \\
\hline J12 & "Lembro da minha infância". \\
\hline $\mathbf{J 1 3}$ & "Minha história foi muito boa". \\
\hline $\mathbf{J 1 4}$ & "Tive uma infância muito boa". \\
\hline $\mathbf{J 1 5}$ & - \\
\hline
\end{tabular}

Fonte: dados da Pesquisa. 
É visível, em algumas das histórias de vida que o seu envolvimento com atos ilícitos, demonstram, não raras vezes, a ausência da presença dos pais ou a falta de controle sobre eles, no que se refere à educação dentro do lar, principalmente, quando, precocemente começam a ter experiência de rua e passam a infringir.

Nesse procedimento, buscou-se avaliar o nível de aceitação do socioeducando, dentro da unidade aonde ele se encontra cumprindo a medida socioeducativa em restrição de liberdade.

Observa-se assim que o SINASE é atrelado a outros subsistemas (a saúde, a educação, a assistência social a justiça e a segurança pública) e objetiva monitorar, supervisionar e avaliar o sistema, a política, os programas e as ações (1) sob a responsabilidade do ente federativo ou por ele delegado e (2) voltadas ao atendimento do adolescente desde o processo de apuração e execução da medida socioeducativa (SEDH, 2006).

Pode-se observar que diante de cada infração, o socioeducando, foi influenciado por outra pessoa, alguns adultos, ou outros adolescentes que tem experiência e difundem a ideia de que "para o adolescente não dá nada" (Quadro 11).

Conforme a coleta das informações obtidas, a infância dos socioeducandos foi marcada pelo carinho do grupo familiar, liberdade para brincar com os irmãos ou com "os colegas" residentes no mesmo bairro. Algumas das histórias do seu envolvimento com atos ilícitos demonstram, não raras vezes, a ausência da presença dos pais ou a falta de controle sobre eles, no que se refere à educação dentro do lar, principalmente, quando, precocemente começam a ter experiência de rua e passam a infringir.

Quadro 11: Opiniões dos pesquisados sobre o seu entendimento de ato(s) que foram considerados infração(ões) em sua história de vida. 2019

\begin{tabular}{|c|c|}
\hline Pesquisados & Falas dos Pesquisados \\
\hline J1 & "Apreendido por porte de arma, de propriedade de uma pessoa adulta. Acompanhado pelo \\
conselho tutelar", prestando BO e liberado".
\end{tabular}

Fonte: dados da Pesquisa.

Infelizmente uma cultura de impunidade perpetua-se entre os adolescentes e aliciadores, deixando as famílias perplexas, ao tomarem conhecimento de alguma infração cometida. Nem sempre os pais conhecem quem são os 
colegas dos seus filhos. Ao cometer uma infração o adolescente/jovem, ou a família, em regra geral, desconhecem toda tramitação processual, embora alguns saibam de alguns dos seus direitos e deveres.

Sobre a grave situação de violência entre os jovens nos Estados Unidos, a American Psychological Society (1997), enumerou diversos fatores, como: a punição extrema; estresses relacionados à pobreza; a violência exibida pela televisão; morar em cômodo pequeno para o número de moradores, fracasso no emprego, temperaturas subitamente elevadas, problemas na família, uso de álcool e drogas, e demais conflitos familiares.

Observa-se que, em alguns casos, a família já havia buscado ajuda nos serviços existentes na comunidade para auxiliá-la no processo educativo desse(a) criança/adolescente/jovem que se encontra cumprindo medida socioeducativa de internação (Quadro 12). A vulnerabilidade social é bastante visível nas relações dessas famílias, sejam elas de qualquer modalidade.

Pode-se perceber que antes de uma medida socioeducativa, muitos jovens são reincidentes, pois já havia passado por circunstâncias de conflito com a Lei, mesmo que pequenas infrações escolares. Por isso, os pesquisados não quiseram expressar as condições e o nível escolar que estavam cursando antes de chegar ao Lar do Garoto.

Quadro 12: Opiniões dos pesquisados sobre antes da medida socioeducativa, haver alguma outra situação que envolveu ação da justiça em relação ao pesquisado ou a sua família. 2019

\begin{tabular}{|c|c|}
\hline Pesquisados & Falas dos Pesquisados \\
\hline $\mathbf{J 1}$ & $\begin{array}{c}\text { "Não. Mesmo sendo usuário de drogas, fui atendido pelo Conselho Tutelar (portanto uma arma de fogo } \\
\text { de um adulto) sendo apreendido e logo em seguida liberado" }\end{array}$ \\
\hline $\mathbf{J} 2$ & "Não" \\
\hline $\mathbf{J 3}$ & "Só minha mãe que teve um problema com a justiça" \\
\hline $\mathbf{J 4}$ & "Não" \\
\hline $\mathbf{J 5}$ & "Já fui acompanhado pelo Conselho Tutelar. Coisa da Escola" \\
\hline $\mathbf{J 6}$ & "Já fui apreendido por três vezes. Cumpri medida de L.A" \\
\hline $\mathbf{J 7}$ & "Não. Aminha família foi sempre correta" \\
\hline $\mathbf{J 8}$ & "Apenas comigo" \\
\hline $\mathbf{J 9}$ & "Não, minha família procura ser justa" \\
\hline $\mathbf{J 1 0}$ & "Comigo, sim, mas estou pagando" \\
\hline $\mathbf{J 1 1}$ & "Não. Minha familia é um exemplo para mim, mas não reconheci isso ao meu favor" \\
\hline $\mathbf{J 1 2}$ & "Erros cometidos, considerados graves" \\
\hline $\mathbf{J 1 3}$ & "Comigo. No Passado". \\
\hline $\mathbf{J 1 4}$ & "Não, a família sempre batalhadora" \\
\hline $\mathbf{J 1 5}$ & "Não, minha familia nunca se envolveu em nada errado" \\
\hline
\end{tabular}

Fonte: dados da Pesquisa.

Nos estudos de Moffit e Caspi (2000), foi identificado que eventos na infância podem influenciar na continuidade da prática de infração durante a vida adulta. As práticas parentais percebidas pelo adolescente como severas e conflituosas na infância encontraram significância nos eventos de trajetórias de adolescentes autores de atos infracionais. De acordo Dias (2001), a interação com a família constitui um dos fatores que, juntamente com a escolaridade, mais contribui para o comportamento dos adolescentes em conflito com a lei. Além do mais, jovens com famílias monoparentais são mais suscetíveis a praticaram alguma infração. 
De acordo com as "falas" presentes no Quadro 13, alguns dos socioeducandos têm experiência de Conflito com a Lei dentro do seu contexto familiar. Outros, mesmo não conhecendo alguma das realidades desse processo, deixam-se ser levados por promessas de "ganhos fáceis", sem consequências para a sua vida pessoal e social. São os que são aliciados e, são obrigados a manter-se em silêncio, sob forte pressão por parte do aliciador.

Observa-se que, em alguns casos, a família já havia buscado ajuda nos serviços existentes na comunidade para auxiliá-la no processo educativo dessa criança/adolescente/jovem que se encontra cumprindo medida socioeducativa de internação. A vulnerabilidade social é bastante visível nas relações dessas famílias, sejam elas de qualquer modalidade.

Quadro 13: Falas dos pesquisados sobre o processo que gerou a medida socioeducativa. 2019

\begin{tabular}{|c|c|}
\hline Pesquisados & Falas dos Pesquisados \\
\hline $\mathbf{J 1}$ & "Não tinha noção das consequências que poderiam vir depois". \\
\hline $\mathbf{J 2}$ & "Fiz uma coisa errada. Estou pagando o meu erro". \\
\hline $\mathbf{J 3}$ & "Foi uma coisa ruim". \\
\hline J4 & "Ter me envolvido com coisa que não devia". \\
\hline $\mathbf{J 5}$ & "Estou pagando o que fiz. Tô arrependido". \\
\hline J6 & "Quando recebi a notícia fiquei triste". \\
\hline J7 & "Envolvimento com coisas ilícitas". \\
\hline J8 & "Envolvimento com pessoas influenciadoras". \\
\hline J9 & "Envolvimento com coisa ilícita". \\
\hline $\mathbf{J 1 0}$ & “Atitudes impensadas”. \\
\hline $\mathbf{J 1 1}$ & “Erros fatais, envolvimento sem pensar nas consequências". \\
\hline $\mathbf{J 1 2}$ & "Envolvimento impensado. Não sabia o que poderia acontecer depois". \\
\hline $\mathbf{J 1 3}$ & "Me envolvi com situações complicadas, mas tô saindo". \\
\hline $\mathbf{J 1 4}$ & "Não acreditava nos conselhos da família. Achava caretice. Enfim, errei". \\
\hline $\mathbf{J 1 5}$ & "Não sabia o que podia me acontecer de ruim". \\
\hline
\end{tabular}

Fonte: dados da Pesquisa.

Para Pereira e Sudbrack (2008), um dos principais indutores dos atos infracionais cometidos por jovens/adolescente é o uso direto e indireto das drogas, que na sua fase inicial (de encantamento): atrai o jovem pelo prazer, facilita suas relações e espaços em novas redes de amizades e incita o desejo pela tomada de risco. Posteriormente, sofrem pela descoberta do descontrole em relação à droga, a qual passa a denunciar suas motivações e necessidades. E por fim, buscam o alívio deste sofrimento quando se deparam com a dependência. Assim, entram no mundo dos atos infracionais, que, na maioria das vezes, não saem mais.

Em algumas situações, o socioeducando deixa transparecer o seu nível de desobediência e descrédito nas orientações recebidas dos seus genitores (Quadro 14). Quando pratica a infração, passa a temer pelo desconhecimento de todo processo e buscam o apoio familiar, chegando até a rejeitar, provisoriamente, àqueles colegas com quem convivia, antes de cometer o ato ilícito.

Quadro 14: Falas dos pesquisados sobre as suas práticas de infração. 2019 


\begin{tabular}{|c|c|}
\hline Pesquisados & Falas dos Pesquisados \\
\hline J1 & "Sim. Fiz uma coisa errada mas estou arrependido do que fiz". \\
\hline $\mathbf{J} 2$ & "As influências dos colegas". \\
\hline $\mathbf{J 3}$ & "A gente conversou sobre o assunto e realizamos of fato" acho que é a familia que me acusa". \\
\hline J4 & "É verdade a história que aconteceu comigo". \\
\hline $\mathbf{J 5}$ & "Não sei, doidice, sem experiência. Minha familia não merece isso que eu fiz". \\
\hline J6 & "Eu sempre assumi os meus erros". \\
\hline J7 & "Aconteceu. Agora vou ter que pagar o meu erro". \\
\hline J8 & "Desconhecimento das consequências". \\
\hline J9 & "Eu não tinha ciência do que poderia acontecer". \\
\hline $\mathbf{J 1 0}$ & "Envolvimento com pessoas erradas e incentivo para fazer o que não era certo". \\
\hline J11 & "Aconteceu, vou pagar o meu erro". \\
\hline J12 & "Fui motivado a realizar atos graves e fui punido". \\
\hline $\mathbf{J 1 3}$ & "Aconteceu. Tô ciente do ato". \\
\hline J14 & "Não tinha noção do que poderia me acontecer". \\
\hline J15 & "Não tinha conhecimento do que era medida socioeducativa". \\
\hline
\end{tabular}

Fonte: dados da Pesquisa.

Quanto aos Atos Infracionais cometidos, alguns dos socioeducandos têm experiência de Conflito com a Lei dentro do seu contexto familiar. Outros, mesmo não conhecendo alguma das realidades desse processo, deixam-se ser levados por promessas de "ganhos fáceis", sem consequências para a sua vida pessoal e social. São os que são aliciados e são obrigados a manter-se em silêncio, sob forte pressão por parte do aliciador.

Em algumas situações, os socioeducandos deixam transparecer o seu nível de desobediência e descrédito nas orientações recebidas dos seus genitores. Quando praticam a infração, passam a temer pelo desconhecimento de todo processo, e buscam o apoio familiar, chegando até a rejeitar, provisoriamente, àqueles colegas com quem convivia, antes de cometer o ato ilícito (Quadro 15).

Quadro 15: Falas dos pesquisados sobre as reações dos familiares/responsáveis diante da decisão judicial. 2019

\begin{tabular}{|c|c|}
\hline Pesquisados & Falas dos Pesquisados \\
\hline J1 & "Aceitaram porque acharam que foi uma infração grave". \\
\hline $\mathbf{J} 2$ & "Ficaram triste e teriam que aceitar a decisão judicial". \\
\hline $\mathbf{J 3}$ & "Meus pais ficaram muito tristes diante dessa situação". \\
\hline J4 & "Fiquei muito triste, porque não precisava passa por isso". \\
\hline J5 & "Prá família, o mundo caiu". \\
\hline J6 & "Minha família ficou irada, sem reação". \\
\hline J7 & "Ficaram muito triste. Foi uma reação meio assustadora". \\
\hline J8 & "A minha família ficou muito triste". \\
\hline J9 & "Decepção e tristeza". \\
\hline $\mathbf{J 1 0}$ & "Preocupação, tristeza e situações constrangedoras". \\
\hline J11 & "Foi muito sofrimento, choro e desespero". \\
\hline J12 & "Preocupados com situação, pois não esperava que acontecesse comigo". \\
\hline J13 & "Foi meio constrangedor para a família". \\
\hline J14 & "Tristeza. Foi dificil para acreditar". \\
\hline J15 & "Decepção e tristeza". \\
\hline
\end{tabular}

Fonte: dados da Pesquisa.

Os socioeducandos demonstram, em sua maioria, que a família tem um papel fundamental na sua vida, contudo, eles agem como se ignorasse essa importância, quando se encontra em situação processual, por alguma 
infração cometida, os valores familiares se tornam mais fortes e há muita revelação de afeto entre eles e o apoio advindo dos familiares torna-nos menos fragilizados diante da situação que terão de enfrentar.

Portanto, segundo a CF/88 é dever da família, da sociedade e do poder público assegurar à criança e ao adolescente, com absoluta prioridade, o direito à vida, à saúde, à alimentação, à educação, ao lazer, à profissionalização, à cultura, à dignidade, ao respeito, à liberdade e à convivência familiar e comunitária, além de colocá-los a salvo de toda forma de negligência, discriminação, exploração, violência, crueldade e além da opressão (BRASIL, 1988).

Em relação às falas dos pesquisados (Quadro 16), abordaram que os socioeducandos ao chegarem à Unidade, no momento do acolhimento, eles demonstram ansiedade e muita tristeza pela realidade que terão de enfrentar. É importante que o técnico de referência que procedeu ao acolhimento saiba simpatizar com ele, demonstrando sensibilidade e respeito. Esses fatores constituem a construção de um bom diálogo e facilita a sua adaptação no ambiente e cria um bom relacionamento com a equipe multidisciplinar e com os demais socioeducandos.

Quadro 16: Opiniões dos pesquisados sobre como foram/estão sendo os contatos e envolvimentos com os serviços prestados pelo Lar do Garoto. 2019

\begin{tabular}{|c|c|}
\hline Pesquisados & Falas dos Pesquisados \\
\hline $\mathbf{J 1}$ & "Precisa melhorar". \\
\hline $\mathbf{J} 2$ & “A saúde precisa melhorar. O que mais me incomoda são as algemas. São constrangedoras”. \\
\hline J3 & "Mais ou menos. As algemas causam constrangimentos". \\
\hline J4 & “Está bem”. \\
\hline J5 & "Um ensino muito grande. Aqui não é lugar para pessoa de bem ficar”. \\
\hline J6 & "São bons os serviços, mas precisa melhorar". \\
\hline $\mathbf{J} 7$ & "É bom os atendimentos dos profissionais, mas vale dizer que o atendimento à saúde, é muito precária". \\
\hline J8 & "São bons, porém, precisam ser melhorados". \\
\hline J9 & "Os profissionais são bons, consigo entender e evoluir com as orientações e cumprir metas". \\
\hline J10 & "A Instituição precisa melhorar". \\
\hline J11 & "Os técnicos nos orientam nas nossas mudanças, fortalecendo a nossa familia”. \\
\hline $\mathbf{J 1 2}$ & "Os profissionais orienta agente para o projeto de vida". \\
\hline $\mathbf{J 1 3}$ & "São bons os profissionais, a gente quando é atendido, fica leve a consciência" \\
\hline $\mathbf{J 1 4}$ & "A equipe é boa. Confiável". \\
\hline $\mathbf{J 1 5}$ & "Os técnicos são bons. Consigo entender as orientações". \\
\hline
\end{tabular}

Fonte: dados da Pesquisa.

Conforme Dameda (2017) são os próprios profissionais do CRAS que vão criando estratégias para que a relação entre eles se efetive e que o trabalho consiga alcançar seus objetivos. Eles almejam, por meio de atendimentos mais qualificados, com escuta acolhedora, auxiliar no agenciamento de novos atores e na expansão da rede na produção de subjetividades dos adolescentes.

Na opinião dos socioeducandos, a convivência na unidade deixa muito a desejar, quando se trata da garantia dos seus direitos à alguma modalidade de assistência (Quadro 17). Para eles, os serviços que lhes são assegurados devem ser melhores e devem funcionar dentro da instituição, assegurando maior agilidade no atendimento à demanda.

Quadro 17 - Opiniões dos pesquisados sobre as regras e encaminhamentos relacionados às medidas socioeducativas. 2019

\begin{tabular}{|c|c|}
\hline Pesquisados & Falas dos Pesquisados \\
\hline J1 & “Aceitaram porque acharam que foi uma infração grave. ” \\
\hline J2 & "A minha vida era muito boa, mas infelizmente aconteceu isso". \\
\hline
\end{tabular}

COURA, V. T.; ALBUQUERQUE, H. N. Adolescentes em conflito com a lei: um olhar sobre o processo educacional institucional. Open Minds International Journal. São Paulo, vol. 1, n. 3: p. 137-157, Set, Out, Nov, Dez/2020. 


\begin{tabular}{|c|c|}
\hline J3 & "Normal, quando sair". \\
\hline J4 & "Sim. Aprendi dar valor a minha liberdade". \\
\hline J5 & "Mudar de vida. Mudar de cidade. Já paguei sem dever, fui envolvido em uma situação dificill". \\
\hline J6 & "Alguém chama para fazer esses atos, mas agora estou experiente e sei dizer um não. Não aceito convite \\
\hline J7 & para cometer infrações". \\
\hline J8 & "Sim. Estou privado de liberdade". \\
\hline J9 & "Sim. Aprendi a valorizar a liberdade". \\
\hline J10 & "Sim, a liberdade é tudo". \\
\hline J11 & "Sim, privado de liberdade é triste". \\
\hline J12 & "Com certeza, atinge a pessoa de todas as formas". \\
\hline J13 & "Sim. Aprendi a dar valor a dar valor à liberdade". \\
\hline J14 & - \\
\hline J15 & - \\
\hline
\end{tabular}

Fonte: dados da Pesquisa.

Ao cometer a infração, o socioeducando sofre algum tipo de discriminação, às vezes, por parte de alguns dos membros da família, que ao tomar conhecimento do fato, reage com indignação. Gradativamente, as coisas vão voltando à normalidade, e a família vai tomando atitudes que vem a beneficiar o socioeducando na sua mudança de conduta, preparando-o para enfrentar a nova realidade. Na internação, o socioeducando pode refletir sobre o seu projeto de vida, com ajuda de profissionais que o atende e contribui com as orientações imprescindíveis para a construção de um "novo caminhar” (Quadro 18).

Quadro 18: Opiniões dos pesquisados sobre haver diferença em suas vidas, com relação ao antes e ao após das medidas socioeducativas. 2019

\begin{tabular}{|c|c|}
\hline Pesquisados & Falas dos Pesquisados \\
\hline $\mathbf{J 1}$ & $\begin{array}{c}\text { "No início foi muito ruim. Longe da família, no meio de pessoas estranhas e tinha que me acostumar com as } \\
\text { normas da Unidade e obedecer às regras e a disciplina apresentada por meio de encaminhamentos seja } \\
\text { para audiências ou atendimento médico". }\end{array}$ \\
\hline $\mathbf{J} 2$ & $\begin{array}{c}\text { "Regras tem que ter, para que a casa melhore" Encaminhamentos, um pouco constrangedor: algema e } \\
\text { policia. Escolta". }\end{array}$ \\
\hline $\mathbf{J 3}$ & "Passei um tempinho para me acostumar as regras da unidade, mas está tudo bem". \\
\hline J4 & "Boa. Aprendi muito com a medida, pois aprendemos a dar valor a liberdade e aos nossos pais". \\
\hline $\mathbf{J 5}$ & "Os encaminhamentos para mim foi rápido, ligeiro, pra ser atendido na questão de saúde". \\
\hline J6 & "Os encaminhamentos precisam ser melhor em todos os aspectos". \\
\hline J7 & "Precisa melhorar muito, principalmente remédios que não tem". \\
\hline J8 & "Encaminhamentos realizados sob a vigilância de escoltas e tornam-se demorados e constrangedores". \\
\hline J9 & $\begin{array}{c}\text { "Vejo que é necessário os atendimento médicos, porém, constrangedores por ser conduzido algemado e } \\
\text { com escolta". }\end{array}$ \\
\hline $\mathbf{J 1 0}$ & "Precária a estrutura em relação aos atendimentos à saúde". \\
\hline J11 & $\begin{array}{c}\text { "Contamos com a assistência dos técnicos para fazer os encaminhamentos, porém, seria ótimo que a } \\
\text { unidade oferecesse os serviços necessários". }\end{array}$ \\
\hline $\mathbf{J 1 2}$ & $\begin{array}{c}\text { "Seria importante que a instituições oferecesse os atendimentos que a gente precisa: Médico e } \\
\text { Odontológico". }\end{array}$ \\
\hline $\mathbf{J 1 3}$ & "Precisa melhorar muito a questão saúde". \\
\hline $\mathbf{J 1 4}$ & "O atendimento médico não é bom. Somos encaminhados com algemas e escolta". \\
\hline $\mathbf{J 1 5}$ & Precisa melhorar os atendimentos médicos e odontológicos \\
\hline
\end{tabular}

Fonte: dados da Pesquisa. 
O processo socioeducativo é interpretado pelos socioeducandos com sendo uma ação punitiva pela infração por eles praticada. Estão dispostos, segundo eles, a cumprir o que foi determinado pela justiça. Propõem-se a construir um projeto de vida, afastar-se das "certas amizades" e de pessoas que os influenciam para ações ilícitas (Quadro 19).

Quadro 19: Percepção dos pesquisados sobre o processo que estão vivenciando em relação a medida socioeducativa. 2019.

\begin{tabular}{|c|c|}
\hline Pesquisados & Falas dos Pesquisados \\
\hline $\mathbf{J 1}$ & $\begin{array}{c}\text { "Era assíduo, tinha dificuldade na aprendizagem e não tinha muito interesse pela escola. Aprendi pouco a } \\
\text { ler e a escrever. Faltava com frequência à escola. Agora tenho mais interesse pelos estudos e tenho } \\
\text { conseguido evoluir um pouco, sendo mais atento as atividades propostas pelos professores". }\end{array}$ \\
\hline $\mathbf{J 2}$ & "Cumprir o que o Juiz determinar". \\
\hline $\mathbf{J 3}$ & "Estou tentando me adaptar, não é fácil ser privado de liberdade". \\
\hline $\mathbf{J 4}$ & "Um aprendizado". \\
\hline $\mathbf{J 5}$ & "É preocupante. Aprendi muito durante esses dois meses. Está sendo um aprendizado". \\
\hline $\mathbf{J 6}$ & "Tô pagando pelo que o que eu fiz. Tô preparado para voltar à sociedade" \\
\hline $\mathbf{J 7}$ & "Pagar o que fiz". \\
\hline $\mathbf{J 8}$ & Preciso dar mais atenção à minha familia e me afastar de pessoas que só querem o meu mal". \\
\hline $\mathbf{J 9}$ & "Pagar o erro cometido" \\
\hline $\mathbf{J 1 0}$ & "Reconhecer o erro e construir uma nova história". \\
\hline $\mathbf{J 1 1}$ & "É o projeto de vida: mudanças e comportamento". \\
\hline $\mathbf{J 1 2}$ & "Pagar pelo ato que cometi". \\
\hline $\mathbf{J 1 3}$ & "Pagar o meu erro". \\
\hline $\mathbf{J 1 4}$ & "Quero dar atenção à minha família". \\
\hline $\mathbf{J 1 5}$ & "Pagar o erro cometido e ficar livre da justiça". \\
\hline
\end{tabular}

Fonte: dados da Pesquisa.

Por se tratar de uma unidade socioeducativa, a equipe multidisciplinar, desenvolve um planejamento com atividades que contemplem a todos socioeducandos, conforme as habilidades de cada um, respeitando as peculiaridades de cada um deles. As atividades buscam desenvolver, principalmente a socialização, e por isso a participação deles é satisfatória, dentro do processo educativo (Quadro 20).

Quadro 20: Falas dos pesquisados sobre as atividades que já participaram no decorrer da medida socioeducativa. 2019

\begin{tabular}{|c|c|}
\hline Pesquisados & Falas dos Pesquisados \\
\hline J1 & "Continuar estudando, trabalhar, ajudar a familia e construir a minha família e fazer um curso superior. \\
\hline J2 & Ainda não decidi qual será a profissão". \\
\hline J3 & "Atividades escolares, esporte e outras". \\
\hline J4 & "Sim. Jogo bola, brinco de dominó e faço atividades propostas pela escola". \\
\hline J5 & "Sim. Jogo de futebol e atividades na casa e na escola também". \\
\hline J6 & "Não participo das atividades esportivas; não posso me misturar. (facção)". \\
\hline J7 & "Foi um monte de curso: energia solar, computação e hortaliças". \\
\hline J8 & "Não participei de atividades esportivas". \\
\hline J9 & "Diversas. Algumas direcionadas pela escola e outras aplicadas dentro do processo educativo. \\
\hline J10 & "Várias atividade propostas pela escola". \\
\hline J11 & "Foram várias atividades oferecidas pela escola e pela unidade". \\
\hline J12 & "Várias atividades propostas pela instituição e atividades escolar". \\
\hline J13 & "Participo de todas atividades que oferecem". \\
\hline J14 & "Participo das atividades oferecidas pela escola". \\
\hline J15 & "Várias atividades são oferecida. Participo de todas". \\
\hline
\end{tabular}

Fonte: dados da Pesquisa.

$\mathrm{Na}$ interpretação dos socioeducandos, as famílias mesmo lhes dando apoio, acham que eles "tem de pagar pelos seus erros". As famílias têm uma visão distorcida da socioeducação. O caráter educativo tem para elas a

COURA, V. T.; ALBUQUERQUE, H. N. Adolescentes em conflito com a lei: um olhar sobre o processo educacional institucional. Open Minds International Journal. São Paulo, vol. 1, n. 3: p. 137-157, Set, Out, Nov, Dez/2020. 
conotação de punitiva. Desse modo, elas ajudam-nos a manter-se com mais calma dentro da unidade, porém, são conscientes, também dos seus direitos. Sabem que a cada seis meses, dá-se uma avaliação, conforme estabelece o ECA, pela equipe multidisciplinar que emitirá a sua opinião sobre se ele está ou não apto para voltar ao convívio familiar e social, e elas acompanham fielmente a esse procedimento (Quadro 21).

Quadro 21: Opiniões dos pesquisados sobre o que seus familiares pensam sobre a medida socioeducativa. 2019

\begin{tabular}{|c|c|}
\hline Pesquisados & Falas dos Pesquisados \\
\hline J1 & "Espero que as pessoas entendam que cometi um erro e já paguei por ele." \\
\hline $\mathbf{J} 2$ & "É um aprendizado, Tenho refletido muito. Quero mudar de vida". \\
\hline $\mathbf{J 3}$ & Para a minha familia é normal. Errei e tenho que pagar". \\
\hline $\mathbf{J 4}$ & "A família fica triste, pois estou perdendo tempo na minha vida”. \\
\hline $\mathbf{J 5}$ & "Para minha familia é péssimo e para mim foi um aprendizado". \\
\hline J6 & "Tem mais maturidade para resolver qualquer situação". \\
\hline J7 & "Minha familia diz que cometi a infração e tenho que pagar". \\
\hline J8 & $\begin{array}{l}\text { "Reconhecem o meu erro e esperam que ao cumprir a medida que me foi aplicada, eu volte a viver na } \\
\text { comunidade sem problemas. }\end{array}$ \\
\hline J9 & "Eles reconhecem o meu erro, tenho que refletir sobre o processo punitivo". \\
\hline J10 & "Cumprir o que foi determinado pela Lei". \\
\hline J11 & Minha família me dá apoio e espera que eu não faça mais nada errado”. \\
\hline $\mathbf{J 1 2}$ & "Minha família acha que devo pagar pela infração que cometi". \\
\hline J13 & "Pagar o que eu devo, mas é dificil para a família" \\
\hline $\mathbf{J 1 4}$ & "Procuro reconhecer o meu erro e ficar em paz com a família". \\
\hline J15 & "Ficaram tristes, mas tô pagando o que eu fiz". \\
\hline
\end{tabular}

Fonte: dados da Pesquisa.

A compreensão dos pesquisados é de que "não tem amigos", a família é quem lhes dá a assistência, enquanto estão em restrição de liberdade. Não desprezam, porém àqueles colegas com quem sempre brincou, pois alguns cresceram na mesma rua e desde cedo são conhecidos. Alguns deles desconhecem o que seja uma medida socioeducativa e estão cientes de que continuarão tendo um bom relacionamento após ficar em liberdade (Quadro 22).

Quadro 22: Falas dos pesquisados sobre as opiniões dos seus amigos sobre a medida socioeducativa. 2019

\begin{tabular}{|c|c|}
\hline Pesquisados & Falas dos Pesquisados \\
\hline J1 & "Não tenho facilidade na comunicação pela internet". \\
\hline J2 & "Vão me receber numa boa, mas vou me distanciar um pouco dessas pessoas". \\
\hline J3 & "Eles não conseguem entender o que aconteceu comigo". \\
\hline J4 & "Vão me receber bem, sem nenhum problema". \\
\hline J5 & "Uns acham bom e outros acham péssimos". \\
\hline J6 & "Vão me receber muito bem. Não tenho problemas com a comunidade. Desde pequeno convivi com eles". \\
\hline J7 & "Os meus amigos são os meus pais e irmãos". \\
\hline J8 & "A maioria reconhece o objetivo da medida". \\
\hline J9 & "Reconhecer o ato, cumprir a decisão judicial e seguir em frente". \\
\hline J10 & "Vão me receber de braços abertos, sem exclusão na comunidade". \\
\hline J11 & "Meus amigos são os meus familiares". \\
\hline J12 & "Meu amigos vão me receber de boa". \\
\hline J13 & "Vão me receber numa boa". \\
\hline J14 & "Meus amigos é a minha familia". \\
\hline J15 & "Os amigos me receberão bem, logo que eu pagar pelo meu erro". \\
\hline
\end{tabular}

Fonte: dados da Pesquisa. 
Quanto às atividades ocupacionais, observa-se que cada um dos socioeducandos procuram conseguir dinheiro de maneira diversificada. Não têm qualificação para o trabalho e se dispõem a fazer o que aparecer, inclusive atos ilícitos. É perceptível o nível da baixa escolaridade entre os socioeducandos. Há muito desinteresse pelos estudos e há pouca valorização pela educação, em regra quase geral. Alguns se justificam pelo fato de que os pais também não se esforçaram para estudar e aceitam a sua decisão em abandonar a escola.

Há também, o fato de algumas famílias incentivarem os filhos a estudarem apenas para que continuem recebendo o benefício social (Bolsa Família), que funciona como complemento da renda familiar ou é apenas o recurso que a família dispõe para sua sobrevivência.

No entendimento dos socioeducandos, eles deverão dar mais valor à escola e se interessar mais pelos estudos. Foi no cumprimento da medida socioeducativa que lhe foi imposta, através das orientações dadas pela equipe multidisciplinar que houve um despertar para a tomada de uma nova consciência, com vistas a mudança de comportamento.

Vê-se assim, em cada um dos socioeducandos pesquisados uma grande vontade de provocar mudança em sua vida. Alguns não conseguem definir o que pretende fazer ao ficar em liberdade, e estão indecisos no que almejam para suas vidas. A imaturidade, a ansiedade e até o medo, tornam-nos fragilizados ante a vida que lhes espera lá fora.

Para alguns dos socioeducandos que já definiram o que pretendem fazer após ficar em liberdade, obedecer às orientações da família é considerado um dos meios principais para atingir os objetivos que se propõem, seguido do propósito de se afastar das más amizades que os influenciam negativamente.

Outras perspectivas entre eles e a de se fortalecerem espiritualmente, e apresentam tal vontade fazendo uso de alguns amuletos que simbolizam a fé.

Observa-se nas respostas de alguns dos pesquisados que há uma vontade grande de se firmar em alguma coisa que possa lhe proporcionar uma melhor qualidade de vida e, quem sabe, libertar-se de alguns hábitos que não lhes favorecem, e buscar desenvolver habilidades produtivas e atividades edificadoras e quem sabe praticar o que foi aprendido na unidade por meio de trabalhos manuais, ou praticar o que foi aprendido através dos cursos oferecidos.

\section{Considerações Finais}

O contexto social no qual esses adolescentes pesquisados convivem é repleto de circunstâncias que induzem às escolhas erradas ou caminhos socialmente diferentes. Alguns dos socioeducandos têm experiência de Conflito com a Lei dentro do seu contexto familiar. Outros, mesmo não conhecendo alguma das realidades desse processo, deixam-se ser levados por promessas de "ganhos fáceis", sem consequências para a sua vida pessoal e social. São os que são aliciados e, são obrigados a manter-se em silêncio, sob forte pressão por parte do aliciador.

Os pesquisados não quiseram expressar as condições e o nível escolar que estavam cursando antes de chegar ao Lar do Garoto, pois antes de uma medida socioeducativa, muitos jovens são reincidentes, pois já havia passado por circunstâncias de conflito com a Lei, mesmo que pequenas infrações escolares.

Os socioeducandos demonstraram, em sua maioria, que a família tem um papel fundamental na sua vida, contudo, eles agem como se ignorasse essa importância, quando se encontra em situação processual, por alguma 
infração cometida, os valores familiares se tornam mais fortes e há muita revelação de afeto entre eles e o apoio advindo dos familiares torna-nos menos fragilizados diante da situação que terão de enfrentar.

Esses fatores contribuem para que a sociedade, inadvertidamente, atribua todo tipo de violência e considere o Estatuto da Criança e do Adolescente como sendo "um instrumento que favorece à marginalidade" e diante de tal entendimento lutam para que a maioridade penal seja reduzida para os 16 (dezesseis) anos.

É um tema polêmico porque ele envolve uma série de questões de ordem jurídico-sociais e todas se deparam com a maior problemática que o problema da deseducação, da falência do sistema presidiário que funciona como sendo ineficiente por não cumprir o papel educativo que deveria executar.

Ao praticar a infração, o adolescente é encaminhado à delegacia especializada da Infância e Juventude, onde se lavra o Boletim de Ocorrência - B.O, seguindo-o para o Ministério Público que fará a sua Representação. Conforme a gravidade do ato praticado, o MP pode solicitar a sua Internação Provisória - Medida Cautelar - que não deverá ultrapassar de (quarenta e cinco) dias. Na audiência de Apresentação, o socioeducando poderá receber uma internação definitiva, que é considerada a mais gravosa de todas.

A internação não poderá ultrapassar de três anos, sendo o adolescente/jovem avaliado semestralmente. $\mathrm{O}$ artigo $42 \S 2^{\circ}$ estabelece que "A gravidade do ato infracional, os antecedentes e o tempo de duração da medida não são fatores que, por si, justifiquem a não substituição da medida por outra menos grave". O tempo da internação deve ser contada a partir de quando ele chegou à unidade.

Outro fator preocupante em relação ao socioeducando é o nível de escolaridade, bem como o seu interesse pelos estudos. Observa-se que grande número deles, é obrigado a frequentar a escola por causa do benefício que a família recebe para complementar a renda familiar. Na unidade, há uma escola Estadual, formal. Há obrigatoriedade, dentro do processo socioeducativo da unidade, com carga horária integral e é um item considerado relevante, na sua avaliação a cada semestre, quando a equipe multidisciplinar, agentes socioeducativos, direção e advogado, optam pela sua continuidade ou desinternação, sugerindo a extinção da medida ou progressão de regime.

No caso da progressão, o socioeducando será encaminhado ao CREAS para cumprir uma medida socioeducativa de liberdade assistida ou de Prestação de Serviços à comunidade. A liberdade assistida, quanto ao tempo, é semelhante à medida de internação: tempo mínimo de 6 (seis) meses, até 3(três) anos, com avaliação semestral. A prestação de serviços à comunidade não pode passar de 6 (seis) meses.

Em todos os processos socioeducativos é importante a participação da família. Temos algumas famílias que pelo fato de residirem distantes, não tem contatos com os seus adolescentes/jovens com frequência. Isso é resultado de baixas condições econômicas e educacionais. A oportunidade de inclusão no mercado de trabalho, as diferenças de gêneros e etnia, são fatores que, não raras vezes, são decisivos na vida do adolescente/jovem que necessitam de apoio e direcionamento para não ser reincidente da infração por ele praticada e pela qual cumpriu a medida que lhe foi imposta. 


\section{REFERÊNCIAS}

APS. AMERICAN PSYCHOLOGICAL ASSOCIATION. Reducing violence: a research agenda. APS Observer Report, n. 5. Washington, DC: Autores, 1997.

BERNARDO, J. F. Competência moral e perfil de profissionais que atendem o adolescente em conflito com a lei. 2011.

BRASIL. Constituição Federal. Brasília, DF: Senado, 1988.

BRASIL. Estatuto da Criança e Adolescente. Lei 8.069, de 13 de julho de 1990. Brasília, 1990.

BRASIL. Conselho Nacional dos Direitos da Criança e do Adolescente - SINASE, junho de 2006.

BRASIL. Conselho Nacional de Saúde. Resolução n 466, de 12 de dezembro de 2012a. Aprova normas regulamentadoras de pesquisas envolvendo seres humanos. Brasília: Diário Oficial da União, 2013.

CABRAL, T. K. C. Adolescentes em conflito com a lei: um olhar sobre o processo de execução de medida socioeducativa no município de Rio Branco do Sul-Paraná. 2018. 111 f. Dissertação (Mestrado em Tecnologia e Sociedade) - Universidade Tecnológica Federal do Paraná, Curitiba, 2018.

CELISTRE, S. S. Os ciclos de formação no ensino público cearense. 2002. Dissertação (Mestrado em Educação) - Faculdade de Educação, Universidade Federal do Ceará, Fortaleza, 2002.

COSTA, C. R. B. S. F. É Possível Construir Novos Caminhos? Da Necessidade de Ampliação do Olhar na Busca de Experiências Bem-Sucedidas no Contexto Socioeducativo. Estudos e Pesquisas em Psicologia, UERJ/RJ, n. 2, 2005 .

DAMEDA, C. Adolescência e Ato Infracional: cartografia de processos de subjetivação de adolescentes em medida de liberdade assistida. 2017. 214 f. Dissertação (Mestrado em Políticas Sociais e Dinâmicas Regionais) Universidade Comunitária da Região de Chapecó, Chapecó, 2017.

DANTAS, L. M. As representações sociais dos operadores de direito sobre os adolescentes que cumprem medidas socioeducativas. 2016. Monografia de Graduação. Universidade Estadual da Paraíba, Campina Grande, 2016.

DIAS, M. D. F. Adolescentes infratores e não infratores: uma análise comparativa através do CBCL e ESR. 2001. 101 f. Dissertação (Mestrado em Educação) - Universidade Federal de São Paulo, São Paulo, 2001.

FARIA, L. F. A. S. Medidas socioeducativas na ressocialização de adolescentes infratores: visão dos profissionais do CREAS. 2017. Dissertação (Mestrado em Educação) - Centro Universitário das Faculdades Associadas de Ensino, São João da Boa Vista, 2017.

GARCIA, M. S. S. Avaliação e validação de projetos. Senac, 2018.

MOFFIT, T.E.; CASPI, A. Comportamento antissocial persistente ao longo da vida e comportamento anti-social limitado à adolescência: seus preditores e suas etiologias. Rev Port Pedagog, n. 34, p. 65-106, 2000.

PEREIRA, S. E. F. N.; SUDBRACK, M. F. O. Drogadição e atos infracionais na voz do adolescente em conflito com a lei. 2008.

SALIBA, M. G. A Educação como Disfarce e Vigilância: Análise das Estratégias de Aplicação de Medidas Socioeducativas a Jovens Infratores. 2006. 175 f. Tese (Doutorado em Educação) - Faculdade de Filosofia Ciências e Letras, Marília, 2006.

SEDH. Secretaria Especial dos Direitos Humanos. SINASE-Sistema Nacional de Atendimento Socioeducativo. 1 ed. Brasília, DF: SEDH/CONANDA, 2006.

ZANELLA, A.; SEIDEL, E.J.; LOPES, L.F.D. Validação de questionário de satisfação usando análise fatorial. INGEPRO - Inovação, Gestão e Produção, v. 2, n. 12, p. 23-35. 2010.

ZANELLA, L. C. Manual de Organização. 4. ed. São Paulo: Atlas, 86p. 2008. 